\title{
New Hybrid Reluctance Motor Drive
}

\author{
P. Andrada, B. Blanqué, E. Martínez, M. Torrent
}

\begin{abstract}
In this paper a new type of hybrid reluctance motor drive is presented. This new motor is characterized by a stator formed by the combination of independent magnetic structures composed of an electromagnet, the magnetic core with one or several coils wound on it, associated with a permanent magnet disposed between their poles. The rotor has the same configuration of a switched reluctance motor without coils, without magnets and without squirrel cages. A particular case of this hybrid reluctance motor is studied in which the stator consists of three electromagnets with permanent magnets, constituting each one of them one phase of the motor, and the rotor is formed by five salient poles. Then an analysis and simulation of the motor is carried out. Finally, experimental results and a comparison of this type of motor drive with respect switched reluctance motor drives of the same size are shown.
\end{abstract}

Index Terms-- Electric drives, hybrid reluctance motors, switched reluctance motors, electronic power converters.

\section{INTRODUCTION}

$\mathrm{E}$ lectric motors and electric drives are the most important electric loads in the European Union (EU), representing over $70 \%$ of the consumed electricity in industry and about $35 \%$ of the used electricity in the tertiary sector [1].

There is a great potential to improve efficiency in electric motors estimated between $20 \%$ and $30 \%$. This improvement of efficiency results in huge savings of energy and in a significant reduction of gas emissions into the atmosphere. The main actions to achieve this are:

- Use of high efficiency electric motors.

- Use of variable speed electric drives to adjust the speed and torque to the load requirements.

- Optimization of the drive including electric motor, converter, transmission and end-use equipment (pumps, fans, compressors, etc).

Regulation No. 640/2009 of the EU [2] implementing Directive 2005/32/EC of the European Parliament and the Council has set ecodesign requirements for electric motors, according to which minimum values of efficiency, levels IE2 and IE3, are demanded in accordance with IEC 6003430 (2008) [3].

IEC 60034-31 (2010) [4] has proposed, although at informative level, limits to the efficiency of class IE4 (Super Premium), which had already been introduced in IEC 60034-30 where was projected as approximately 15\% of reduced losses compared to IE3. IE4 class is not limited to the three-phase induction motors like the classes IE1, IE2 and IE3, but it is meant to be used in all types of electric motors particularly those fed through static power converter.

Currently, there seems not possible to achieve the

This work was supported by Fundació Equiibrí. The authors are with Electronically Commutated Drives Group (GAECE), Departament d'Enginyeria Elèctrica (DEE). Escola Politècnica Superior d'Enginyeria de Vilanova i la Geltrú (EPSEVG). Universitat Politècnica de Catalunya (UPC), BARCELONATECH. Avinguda Victor Balaguer 1, 08800 Vilanova i la Geltrú, Barcelona, Spain. (e-mail: pere.andrada@upc.edu) efficiency levels specified in IE4 class with three-phase asynchronous induction motors. However, this goal can be achieved using emerging technologies such as brushless DC motors, permanent magnet synchronous motors or switched reluctance motors.

Nowadays, electric mobility has opened a huge market and set new goals to the electric motors and drives. An electric drive for traction should include the following requirements [5]:

- High torque density and high power density.

- Wide speed range at constant power operation.

- High efficiency in all the ranges of torque and speed.

- Overload capability.

- High robustness, high reliability and ease of manufacturing.

- Low torque ripple and low noise.

- Low cost.

Right now, these requirements can be accomplished using: three-phase asynchronous motor drives, brushless DC motor drives, permanent magnet synchronous motor drives or switched reluctance motor drives. Nevertheless brushless DC motor drives and permanent magnet synchronous motor drive start with advantage due to their higher efficiency and higher torque/power density.

Hybrid reluctance motor drives (HRM) can be an alternative to the well established electric drives in the industry, tertiary sector and in the new electric vehicles market because they combine the best of switched reluctance motor (simplicity constructive of the rotor) with the best of brushless DC motors and/or synchronous permanent magnet motors (high torque/power density), adding, in addition, a potential reduction of the mass of the permanent magnets.

Depending on the arrangement of the permanent magnets in the stator HRM can be classified in:

- Doubly salient permanent magnet motors. Motors with salient poles in the stator and the rotor and with magnets embedded in the stator yoke [6-8].

- Flux-switching permanent magnet motors. Motors with salient poles in the stator and the rotor and with magnets embedded inside stator poles [9, $10]$.

This paper presents a new type of hybrid reluctance motor which is characterized by a stator formed by the combination of independent magnetic structures composed of an electromagnet, the magnetic core with one or several coils wound on it, associated with a permanent magnet disposed between their poles. The rotor has the same configuration as that of a switched reluctance motor without coils, without magnets and without squirrel cages.

The motor is controlled by an electronic power converter in which the switching sequence of the phases is generated according to the rotor position determined by a 
speed-position transducer or estimated by means of the voltages and currents of the motor. In this new motor as a result of use these particular independent magnetic structures when there are no currents in the coils; air gap flux is zero. In contrast when currents flow through coils the air gap flux is equal to the flux created by these currents added to the flux produced by permanent magnets. Therefore, this motor has the following advantages:

- Shorter magnetic circuits and as a consequence lower iron losses.

- Fault tolerant motor due to its particular construction

- Better use of materials.

- No cogging torque.

- Higher power density than a switched reluctance motor of the same size.

- Higher efficiency than a reluctance motor the same size.

This paper is organized as follows: Section 2 presents the principle of operation of this hybrid reluctance motor, Section 3 describes a particular case of the hybrid reluctance motor. In section 4 an analysis and simulation of the motor is carried out. Section 5 shows the experimental results and a comparison of this type of motor drive with respect switched reluctance motor drives and finally in section 6 the conclusions from the present study are drawn.

\section{BASIC PRINCIPLE OF OPERATION}

To illustrate the operating principle of the proposed hybrid reluctance motor the following simplified reasoning is exposed. Fig. 1 shows the magnetic circuit of an electromagnet consisting of a fixed part (U shaped), with a coil of $\mathrm{N}$ turns, and a movable part, these parts are built using ferromagnetic materials (laminated electrical steel, $\mathrm{SMC}, .$. ) separated by an air gap. When current flows through the coil a magnetic field is created and produces an electromagnetic force that attracts the moving part, once the forces opposing to the movement have been overcome.

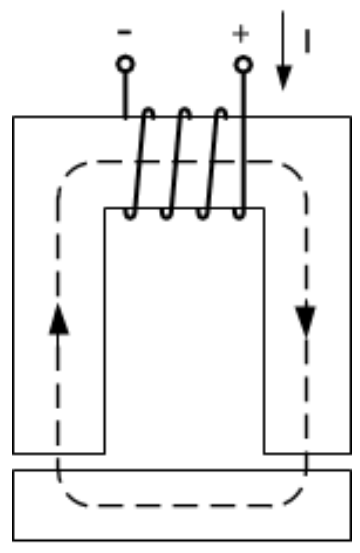

Fig. 1. Electromagnet

Fig. 2 shows the same magnetic circuit of Fig. 1 but with a permanent magnet placed near the air gap, inside the fixed part (U shaped) of the electromagnet. When no current flows through the coil the flux created by the magnet is closed through the fixed part and does not cross the air gap as it is seen in Fig. 2A. But, when a current flows through the coil the flux of the magnet is added to the flux generated by the action of the coil, see Fig. 2B, which originates an electromagnetic attraction force superior to that produced by a conventional electromagnet.

The stator or fixed part of hybrid reluctance machines, motors and generators, can be built using the combination of several electromagnets with permanent magnets while the moving part is a simple structure with salient poles. Thus different types of hybrid reluctance machines can be constructed:

- Single-layer rotary hybrid reluctance machines, with the phases in a single layer in the same plane.

- Multilayer rotary hybrid reluctance machines, with the phases arranged in different parallel planes.

- Linear hybrid reluctance machines.



(A)



(B)

Fig. 2. Electromagnet with permanent magnet. (A) Flux distribution without current flow through the coil. (B) Flux distribution with current flow through the coil

\section{NEW HYBRID RELUCTANCE MOTOR DRIVE}

To demonstrate the operation of the new hybrid reluctance motor drive and for better comparison with other well established drives in the market (SRM and induction motor drives) a three-phase prototype has been designed. The simplest type of the hybrid reluctance machine, i.e. with the phases in a single layer in the same plane, has been chosen. The stator consists of three electromagnets with permanent magnets, constituting each one of them one phase of the motor and the rotor is formed by five salient poles. The stator has to be designed such that for each phase there is a position of alignment of the stator poles with the rotor poles. Thus the angle between the axes of the 
rotor poles has to be $72^{\circ}$, the angle between the position of alignment and the position of non-alignment must be of $36^{\circ}$ and therefore there are 15 strokes per revolution. The cross section of the HRM prototype is shown in Fig. 3 and its nominal characteristics are $3000 \mathrm{rpm} .300$ V D.C., and size IEC 80. Due to this particular construction, which ensures a better use of materials, this motor has in addition short magnetic circuits and independence of phases what it means lower iron losses and fault tolerance.

The electronic power converter is an asymmetric converter, see Fig. 4, that is controlled using hysteresis control for low speed and singe pulse control for high speeds. An incremental encoder has been used as positionspeed transducer.

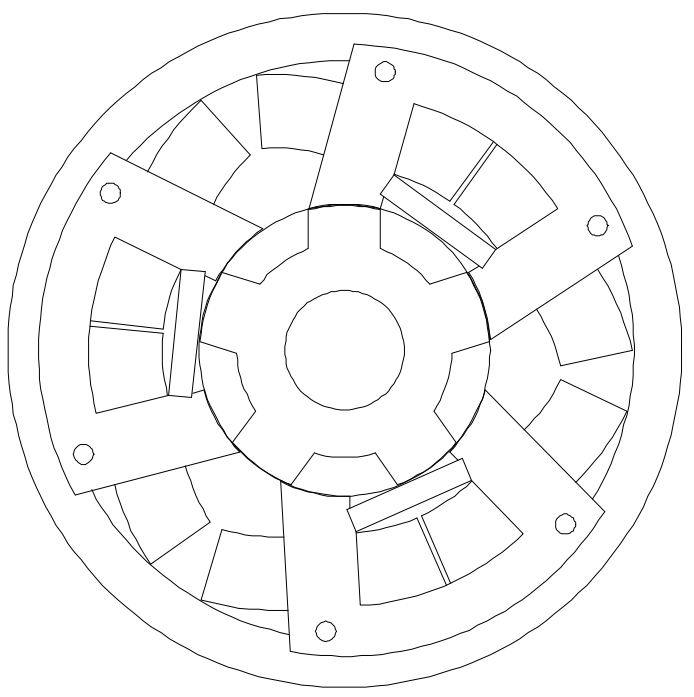

Fig. 3. Cross section of the HRM prototype

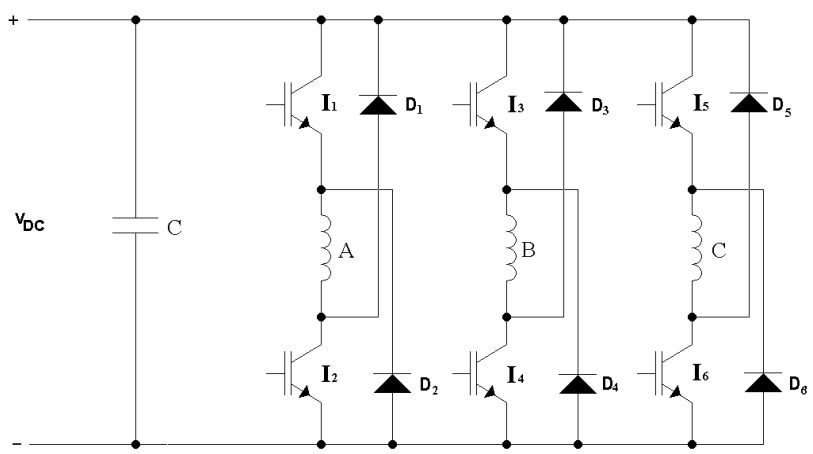

Fig. 4. Power electronic converter

\section{SIMULATION OF THE HYBRID RELUCTANCE MOTOR DRIVE}

A. Finite Element Analysis of the hybrid reluctance motor

The electromagnetic behavior of the prototype has been analyzed using 2D finite elements method. In Fig. 5 the distribution of field lines in different rotor position are represented. Fig. 5A shows the distribution of field lines for the position of alignment, in which the stator poles of one phase are completely aligned with the rotor poles while in Fig. $5 \mathrm{~B}$ is depicted the distribution of field lines for the position of non-alignment.



(A)

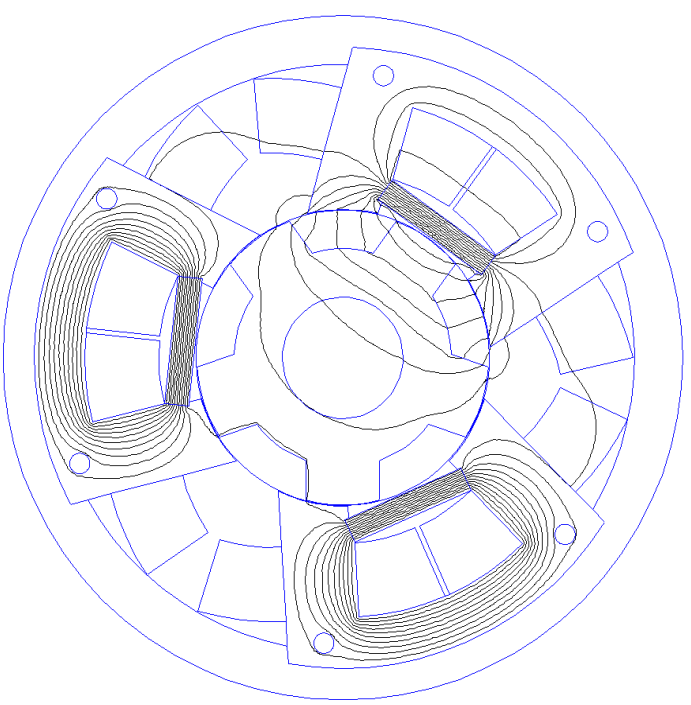

(B)

Fig. 5. Field lines distribution for a current of 5 A. (A) Aligned position. (B) Non-aligned position

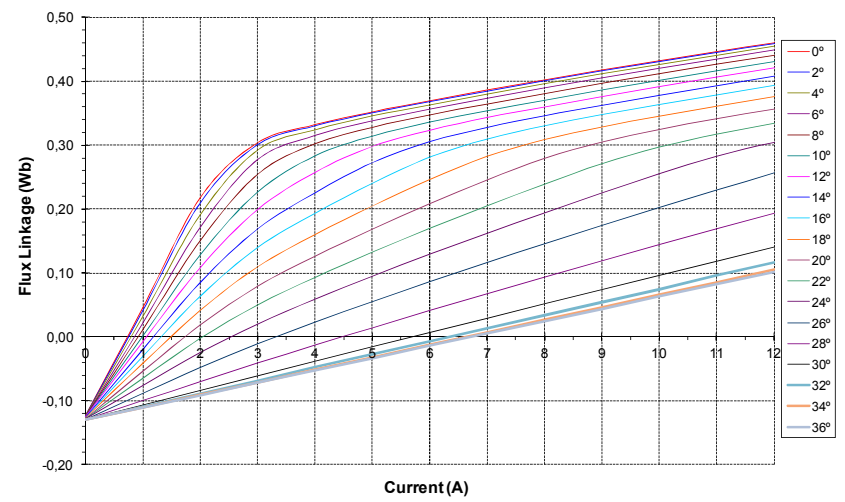

Fig. 6. Magnetization curves of the hybrid reluctance prototype

The magnetization curves, flux linkage $(\psi)$ vs current (I) for different relative positions between stator and rotor $(\theta)$, from the position of alignment $\theta=0^{\circ}$ to the position of nonalignment $\theta=36^{\circ}$ are shown in Fig. 6. Static torque curves, torque compared to the relative position between stator and 
rotor for different values of current, are represented in Fig. 7.

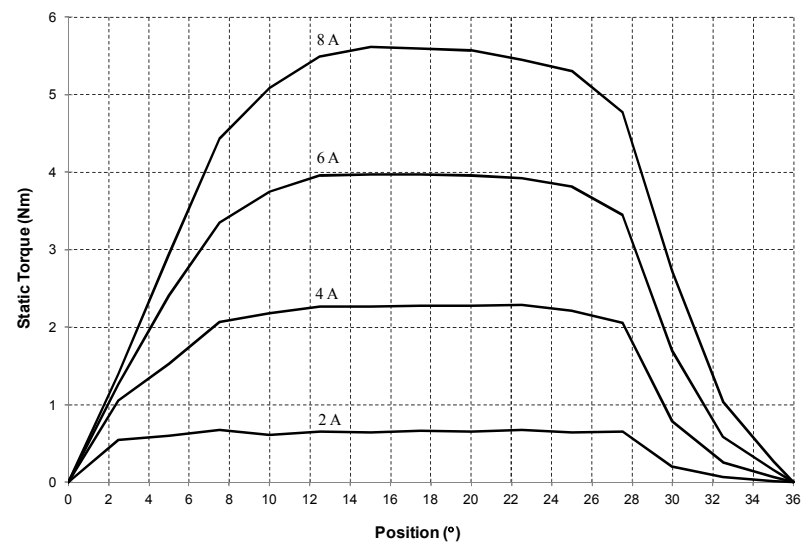

Fig. 7. Static torque curves for the hybrid reluctance prototype

The evolution of the torque due to the interaction between the permanent magnets and the rotor poles versus position when there is no current in the coils is shown in Fig. 8. This torque is usually called cogging torque or detent torque and is an undesirable effect in the operation of the motor. The results derived from Fig. 8 confirm that in this new hybrid motor cogging torque is virtually zero because there are no flux lines that cross the air gap when there is no circulation of current by the coils what it is a clear advantage over other types of hybrid reluctance motors.

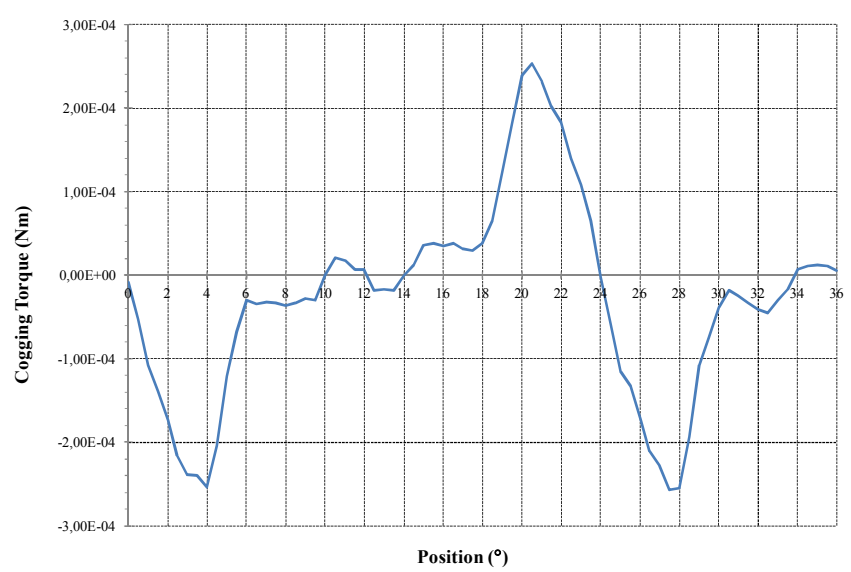

Fig. 8. Cogging torque vs position (without current in the coils)

\section{B. Simulation of the hybrid reluctance motor drive}

Simulation of the hybrid reluctance motor drive considering the motor, the electronic power converter and the control is implemented using Matlab-Simulink and the results obtained of the previous finite element analysis. Fig. 9 shows the waveforms of phase voltage, phase current, phase torque and total torque, and DC bus current at 3000 rpm with a turn-on angle, $\theta_{\mathrm{ON}}$, of $2^{\circ}$ and a turn-off angle, $\theta_{\mathrm{OFF}}$, of $26^{\circ}$. Table I sets out the simulation results derived of Fig. 9.
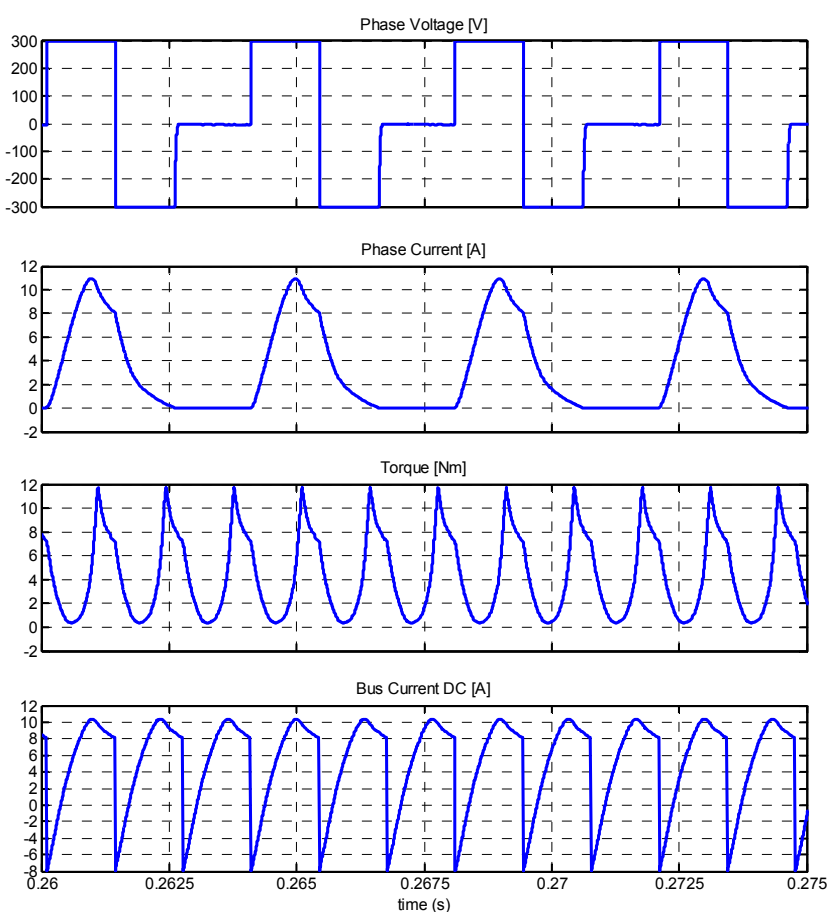

Fig. 9. Waveforms of phase voltage, phase current, torque and bus current DC at $3000 \mathrm{rpm}$, single pulse control and: $\theta_{\mathrm{ON}}=2^{\circ}$ and $\theta_{\mathrm{OFF}}=26^{\circ}$

TABLE I

SIMULATION RESULTS AT 3000 RPM, SINGLE PULSE CONTROL

\begin{tabular}{c|c}
\hline Turn-on angle $\left(\theta_{\mathrm{ON}}\right)$ & $2^{\circ}$ \\
\hline Turn-off angle $\left(\theta_{\mathrm{OFF}}\right)$ & $26^{\circ}$ \\
\hline DC bus voltage & $300 \mathrm{~V}$ \\
\hline DC bus current & $5.235 \mathrm{~A}$ \\
\hline Input power & $1571 \mathrm{~W}$ \\
\hline Phase current (average value) & $3.05 \mathrm{~A}$ \\
\hline Phase current (RMS value) & $4.86 \mathrm{~A}$ \\
\hline Torque & $4.33 \mathrm{Nm}$ \\
\hline Output power & $1.360 \mathrm{~W}$ \\
\hline \multicolumn{2}{c}{ Global efficiency } \\
\multicolumn{2}{c}{$*$ Mechanical losses not considered }
\end{tabular}

\section{EXPERIMENTAL RESULTS AND COMPARATIVE OF HYBRID RELUCTANCE MOTOR DRIVES WITH SRM DRIVES}

An HRM prototype has been built, figures $10 \mathrm{~A}$ and 10 $\mathrm{B}$, show photographs of the stator and rotor. The experimental torque-speed and efficiency-speed characteristics are depicted in Fig. 11, turn-on angle $\theta_{\mathrm{ON}}=4^{\circ}$ and turn off angle $\theta_{\mathrm{OFF}}=28^{\circ}$. It is important to note that efficiency is the global efficiency (MHR + power electronic converter). 


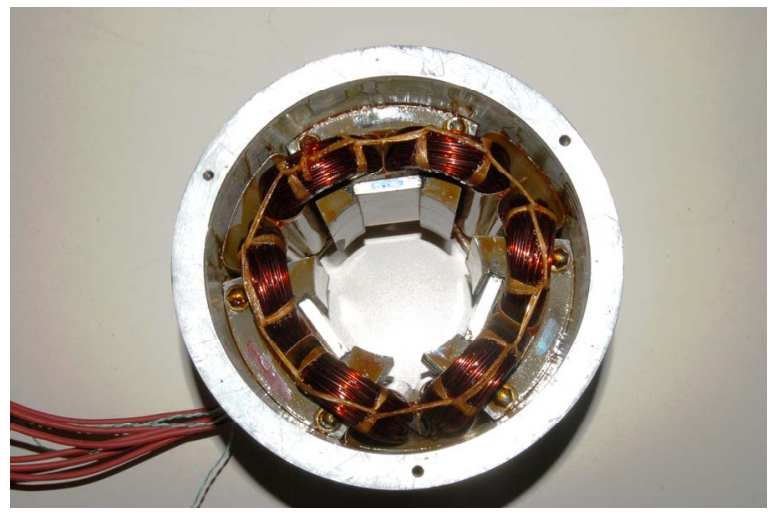

(A)



(B)

Fig. 10. Photograph of the stator (A) and the rotor (B) of the MHR prototype

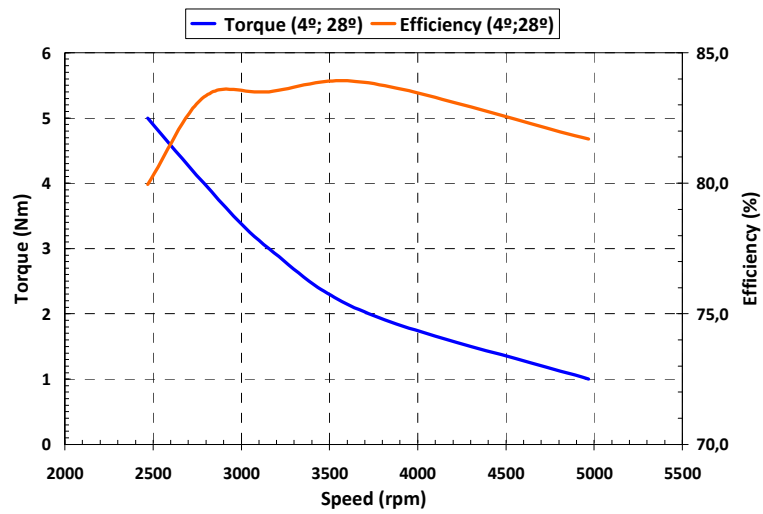

Fig. 11.- Torque-speed and efficiency speed characteristics (single pulse control)

The HRM prototype has been compared with two switched reluctance motors (SRMs), one with 6 stator poles and 4 rotor poles and the other with 12 stator poles and 8 rotor poles, of the same size. In Table II the main parameters and dimensions of the considered motors have been compiled. The experimental static torque curves versus position of the 6/4 SRM and 12/8 SRM are shown in Figs. $12 \mathrm{~A}$ and $12 \mathrm{~B}$, while the experimental static torque curves versus position of the HRM prototype can be seen in Fig 13. From the comparison of these figures it is clear that with this new type of motor can be obtained higher values of torque. From the experimental results and the data presented in reference [11] it can be stated that hybrid reluctance motor drive has a higher efficiency than SRM drives. In addition it can be rated at higher power $(1100 \mathrm{~W})$ than a SRM drive of the same size.

TABLE II

MAIN PARAMETERS AND DIMENSIONS

\begin{tabular}{c|c|c|c}
\hline & HRM & $6 / 4$ SRM & $12 / 8$ SRM \\
\hline Size ICE & 80 & 80 & 80 \\
\hline Rated power (W) & 1100 & 750 & 750 \\
\hline Nominal speed (rpm) & 3000 & 3000 & 3000 \\
\hline DC voltage (V) & 300 & 300 & 300 \\
\hline $\begin{array}{c}\text { Global efficiency at } \\
3000 \text { rpm (\%) }\end{array}$ & 83,8 & 75 & 75 \\
\hline Number of phases & 3 & 3 & 3 \\
\hline $\begin{array}{c}\text { Number of } \\
\text { electromagnets with } \\
\text { permanent magnets }\end{array}$ & 3 & - & - \\
\hline Number of stator poles & - & 6 & 12 \\
\hline Number of rotor poles & 5 & 4 & 6 \\
\hline Stack length (mm) & 63 & 59.65 & 60.25 \\
\hline Rotor diameter (mm) & 60.4 & 59.75 & 65 \\
\hline Air gap (mm) & 0.3 & 0.54 & 0.35 \\
\hline Electric steel grade & $270-50$ & $600-50$ & $600-50$ \\
\hline Mass (g) & 8645 & $6740^{*}$ & $7435^{*}$ \\
\hline
\end{tabular}

*Light alloy frame

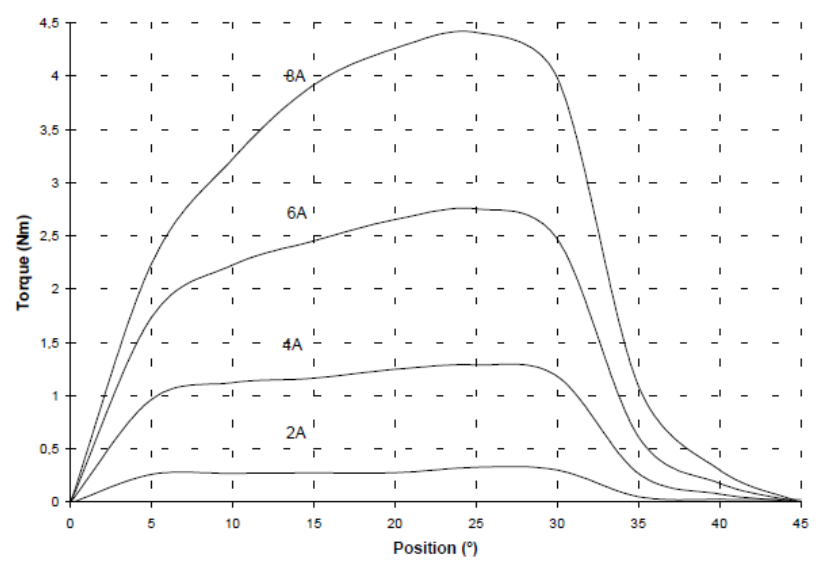

(A)

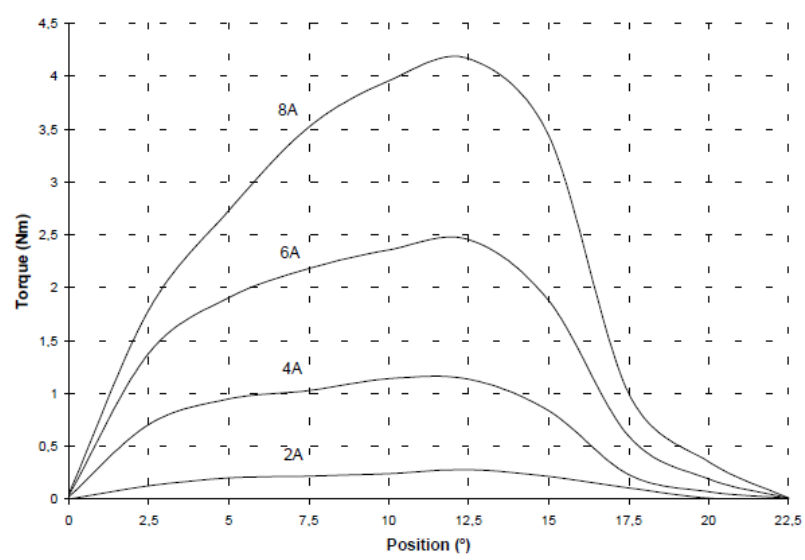

(B)

Fig. 12. Experimental static torque vs position. (A) 6/4 SRM. (B) 12/8 SRM 


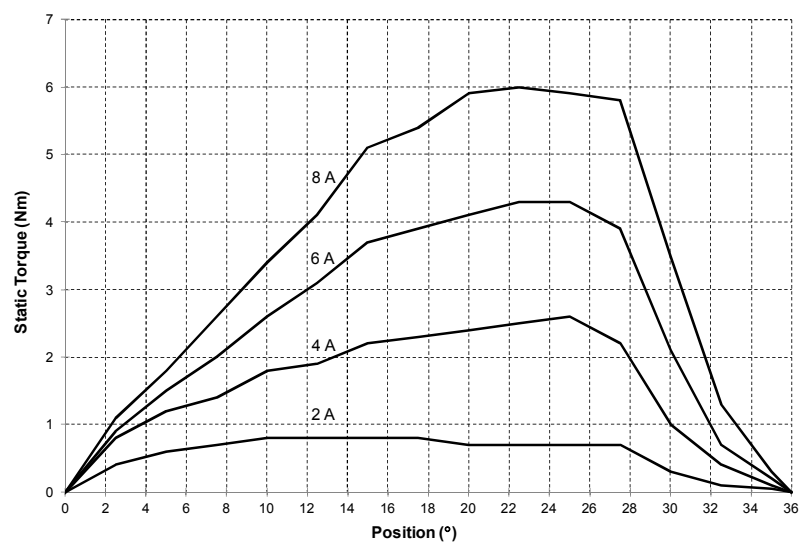

Fig.13. Experimental static torque vs position HRM prototype

\section{CONCLUSIONS}

In this paper a new type of hybrid reluctance motor drive has been presented. A particular case of this type of hybrid reluctance motor is studied in which the stator consists of three electromagnets with permanent magnets, constituting each one of them one phase of the motor and the rotor is formed by five salient poles. From the study and analysis of the new hybrid reluctance motor drive it can be concluded that it is fault tolerant, it has higher efficiency and can be at rated higher power than SRM drives of the same size and that, unlike other hybrid reluctance motor drives, it does not have cogging torque.

\section{AKNOWEDGMENT}

The authors would to like to thank Mr. Francesc Folguera for his support and Mr. Oscar Rolando Ávila and Mr. Xavier Adelantado for their suggestions. They also wish to thank IMA S.L. for providing the permanent magnets used in this research.

\section{REFERENCES}

[1] Anibal T. de Almeida, Joao Fong and Hugh Falkner, "Best Practices in Energy Efficient Industrial Technologies: Motor Systems", Institute for Industrial Productivity, August 2011.

[2] Commission Regulation (EC) No 640/2009 of 27 July 2009 implementing Directive 2005/327 EC of the European Parliament and of the Council with regard to ecodesign requirements for electric motors. Official Journal of the European Union; 23.7.2009.

[3] IEC 60034-30. Rotating electrical machines - Part 30: Efficiency classes of single-speed three-phase cage induction motors.

[4] IEC 60034-31. Guide for the selection and application of energyefficient motors including variable speed applications.

[5] Z.Q.Zhu and D. Howe. «Electrical Machines and Drives for Electric, Hybrid and Fuel Cell Vehicles ». Proceedings of IEEE, Vol 95, No 4, April 2007, pp. 746-765.

[6] Y. Liao, F. Liang and T. A. Lipo. "A Novel Permanent Magnet Motor with Doubly Salient Structure". IEEE Transactions on
Industry Applications, Vol. 31, No. 5. September-October 1995, pp1069-1078

[7] F. Blaabjerg, L. Christensen, P.0. Rasmussen, L. Oestergaard, P. Pedersen. "New Advanced Control Methods for Doubly Salient Permanent Magnet Motor". IAS Annual Meeting 1995, pp. 222-230.

[8] L. Mingyao, C. Ming, E. Zhou. "Design and Performance Analysis of New 12/8 Pole Doubly Salient Permanent-Magnet Motor". ICEMS 2003, pp. 21-23

[9] Y. Amara, E. Hoang, M. Gabsi, M. Lécrivain and S. Allano "Design and comparison of different flux-switch synchronous machines for an aircraft oil breather application" Euro. Trans. Electr. Power 2005; 15, pp. 497-511

[10] W Hua, Z. Q. Zhu, M. Cheng, Y. Pang and D. Howe. "Comparison of Flux-Switching and Doubly-Salient Permanent Magnet Brushless Machines". ICEMS 2005, pp 165-170

[11] P. Andrada, B. Blanqué, E. Martínez, J.I. Perat, J.A. Sánchez and M. Torrent, "Performance comparison of switched reluctance motors with 6/4 and 12/8 structures", ICEM 2002, Brugge, Belgium 2002.

\section{BIOGRAPHIES}

Pere Andrada (M'91) was born in Barcelona (Spain) in 1957. He received the $\mathrm{M}$.Sc. and the $\mathrm{PhD}$. degrees in industrial engineering from the Universitat Politècnica de Catalunya.,(UPC), Barcelona, Spain, in 1980 and 1990 respectively. In 1980 he joined the Department of Electrical Engineering, Universitat Politècnica de Catalunya UPC, where he is currently Associate Professor in the Escola Politècnica Superior d'Enginyeria de Vilanova i la Geltrú (EPSVG). He is member of the Electronically Commutated Group (GAECE). His teaching activities and research interests include design and modeling and control of electrical machines and drives.

Balduí Blanqué was born in Reus (Tarragona, Spain) in 1970. He received the B.S. degree in Telecommunications, the M.S. degree in Telecommunications, and the Ph.D. degree from the Universitat Politècnica de Catalunya (UPC), in Barcelona, Spain, in 1996, 1999, and 2007, respectively. Since 1996, he has been with the Department of Electrical Engineering, Universitat Politècnica de Catalunya (UPC), where he is currently an Assistant Professor in the Escola Politècnica Superior d'Enginyeria de Vilanova i la Geltrú (EPSVG). He is member of the Electronically Commutated Drives Group (GAECE). His teaching activities cover digital design and electronics applications and his research interests include modeling, simulation and control of electrical machines and drives

Eusebi Martínez was born in Barcelona (Spain) in 1960. He received the Engineer degree in industrial engineering from Universitat Politècnica de Catalunya in 1984. He is currently an Assistant Professor, in the Department of Electrical Engineering, Universitat Politècnica de Catalunya, in the Escola Politècnica Superior d'Enginyeria de Vilanova la Geltrú (EPSVG). He is member of the Electronically Commutated Drives Group (GAECE).

Marcel Torrent was born in Menàrguens (Lleida, Spain) in $1965 . \mathrm{He}$ received the $\mathrm{Ph} . \mathrm{D}$. degree in industrial engineering from Universitat Politècnica de Catalunya in 2002. He is currently an Associate Professor in the Department of Electrical Engineering, Universitat Politècnica de Catalunya, in the Escola Politècnica Superior d'Enginyeria de Vilanova i la Geltrú (EPSVG). He is member of the Electronically Commutated Drives Group (GAECE). 